\title{
Construction of Mechanically Reinforced Thermoplastic Polyurethane from Carbon Dioxide-Based Poly(ether carbonate) Polyols via Coordination Cross-Linking
}

\author{
Gaosheng Gu, Jincheng Dong, Zhongyu Duan and Binyuan Liu*
}

check for updates

Citation: Gu, G.; Dong, J.; Duan, Z.; Liu, B. Construction of Mechanically Reinforced Thermoplastic

Polyurethane from Carbon

Dioxide-Based Poly(ether carbonate)

Polyols via Coordination

Cross-Linking. Polymers 2021, 13,

2765. https://doi.org/10.3390/

polym 13162765

Academic Editor: Miguel

Angel Rodríguez-Pérez

Received: 17 July 2021

Accepted: 13 August 2021

Published: 17 August 2021

Publisher's Note: MDPI stays neutral with regard to jurisdictional claims in published maps and institutional affiliations.

Copyright: (C) 2021 by the authors Licensee MDPI, Basel, Switzerland. This article is an open access article distributed under the terms and conditions of the Creative Commons Attribution (CC BY) license (https:// creativecommons.org/licenses/by/ $4.0 /)$
Hebei Key Laboratory of Functional Polymer, School of Chemical Engineering and Technology, Hebei University of Technology, Tianjin 300130, China; ggspolymer@126.com (G.G.); jinchengdongpoly@126.com (J.D.); zyduan@hebut.edu.cn (Z.D.)

* Correspondence: byliu@hebut.edu.cn

Abstract: Using carbon dioxide-based poly(propylene ether carbonate) diol (PPCD), isophorone diisocyanate (IPDI), dimethylolbutyric acid (DMBA), ferric chloride $\left(\mathrm{FeCl}_{3}\right)$, and ethylene glycol (EG) as the main raw materials, a novel thermoplastic polyurethane (TPU) is prepared through coordination of $\mathrm{FeCl}_{3}$ and DMBA to obtain TPU containing coordination enhancement directly. The Fourier transform infrared spectroscopy, ${ }^{1} \mathrm{H}$ NMR, gel permeation chromatography, UV-Vis spectroscopy, tensile testing, dynamic mechanical analysis, $X$-ray diffraction, differential scanning calorimetry, and thermogravimetric analysis were explored to characterize chemical structures and mechanical properties of as-prepared TPU. With the increasing addition of $\mathrm{FeCl}_{3}$, the tensile strength and modulus of TPU increase. Although the elongation at break decreases, it still maintains a high level. Dynamic mechanical analysis shows that the glass-transition temperature moves to a high temperature gradually along with the increasing addition of $\mathrm{FeCl}_{3}$. X-ray diffraction results indicate that TPUs reinforced with $\mathrm{FeCl}_{3}$ or not are amorphous polymers. That $\mathrm{FeCl}_{3}$ coordinates with DMBA first is an effective strategy of getting TPU, which is effective and convenient in the industry without the separation of intermediate products. This work confirms that such Lewis acids as $\mathrm{FeCl}_{3}$ can improve and adjust the properties of TPU contenting coordination structures with an in-situ reaction in a low addition amount, which expands their applications in industry and engineering areas.

Keywords: thermoplastic polyurethane; poly(propylene ether carbonate) diol; isophorone diisocyanate; in-situ reaction; coordination enhancement

\section{Introduction}

Thermoplastic polyurethanes (TPUs) are one of the most interesting types of PUs with versatile applications ranging from consumer products, automobile parts, sporting goods, and electronic/medical devices [1-5]. Polyol is an essential component to generate the soft segments in polyurethane (PU) manufacture, which play significant roles in mechanical properties, chemical and oxidative stability for the resulted TPUs [6-8]. Carbon dioxide-based polyol can be considered as polyether polyol modified by the introduction of carbonate structure, which is a kind of poly(ether carbonate) (PEC) polyols and combines the advantages of polycarbonate polyol and polyether polyol. Attributing to carbonate units, PU based on carbon dioxide polyol possesses high mechanical properties, high hardness, well wear resistance, and fine solvent resistance [9-11]. It is demonstrated that PU obtained from carbon dioxide-based PEC polyols exhibit better hydrolysis resistance and oxidative stability compared with that based on petroleum polyester and polyether type polyols [12,13]. Furthermore, the life cycle assessment studies indicate that the global warming impact of PEC polyols containing $20 \mathrm{wt} . \% \mathrm{CO}_{2}$ is lower than that of conventional polyether-based polyol by 11-19\%, and save fossil resources by $13-16 \%$, possessing environmental and economic benefits [14]. Different from the waxy solid polycarbonate 
polyol, flexible ether linkages in the backbone enable carbon dioxide-based PEC polyol in a liquid state, allowing facile fabrication of TPUs through typical procedures $[15,16]$. So carbon dioxide-based PEC polyol is currently attracting great interest as a promisingly alternative feedstock for the preparation of PUs. Carbon dioxide-based polyols with less carbonate unit content usually possess low viscosity which is favorable to use and process but performs worse in mechanical properties $[17,18]$, for which commercial carbon dioxide-based polyols usually possess low carbonate unit. Then, it makes sense to improve the mechanical properties of TPU from carbon dioxide-based polyols so as to expand the application fields.

Metal-ligand coordination interactions are important kinds of noncovalent bonds, and the bond strength can be tuned by changing the combination of metal salt and ligand in a rather broad range [19-21]. Thermodynamically stable whilst kinetically labile coordination bonds have been introduced into polymer structures in order to improve the mechanical strength of polymeric materials [22-26]. From the applicable viewpoints, the accessibility of the starting materials and the degree of difficulty in synthesizing the ligand and incorporating the ligand into polymeric materials are important and should be mainly considered. Commercially available dimethylolbutyric acid (DMBA) is a good candidate, in which the $-\mathrm{OH}$ groups preferentially react with isocyanate groups [27,28]. Moreover, DMBA has better solubility in different solvents and is regarded as a new generation of green environmental hydrophilic chain extender, which has been widely used in the manufacture of waterborne polyurethanes. Particularly, the carboxylate of DMBA is able to coordinate with metal cations in monodentate, bidentate, or polydentate bindings and various bridging modes $[29,30]$. Besides, we are concerned with that in the preparation of polymers containing metal-coordination, researchers [22-25] generally synthesize polymers with coordination structures first, and then dissolve them in organic solvents or water and further coordinate with metal compounds, which is complex and inconvenient in industrial productions and applications. To improve the drawback, we aim at preparing TPU containing metal-coordination with an in-situ reaction and low addition amount of $\mathrm{FeCl}_{3}$ to expand its practical applications.

Herein, poly(propylene ether carbonate) diol (PPCD) chosen as a representative carbon dioxide-based PEC polyol, TPUs containing coordination enhancement possesses simultaneously high tensile strength and high toughness are successfully prepared by pre-polymerization through an in-situ method [31,32]. The chemical structures, thermal and mechanical properties of resulted polyurethane are inspected by Fourier transform infra-red (FT-IR) spectroscopy, ${ }^{1} \mathrm{H}$ NMR, tensile testing, dynamic mechanical analysis (DMA), and thermogravimetric analysis (TGA).

\section{Materials and Methods}

\subsection{Materials}

PPCD (Industrial Grade) was purchased from Huizhou Dayawan Dazhi Fine Chemical Ltd. (Huizhou, China), whose model is PPCD222 and ${ }^{1} \mathrm{H}$ NMR spectrum and detailed data is shown in Figure S1 and Table S1. Isophorone diisocyanate (IPDI, 99\%), ethylene glycol (EG, 98\%), ferric chloride $\left(\mathrm{FeCl}_{3}, 98 \%\right)$, and DMBA $(99 \%)$ were purchased from Heowns Opde Technologies Ltd. (Tianjin, China). Dibutyltin dilaurate (DBTDL, 97.5\%) was purchased from J\&K Chemical Ltd. (Beijing, China). EG was properly purified by vacuum distillation. PPCD was dehydrated under vacuum at $110^{\circ} \mathrm{C}$ before use. DMBA was dehydrated under vacuum at $100{ }^{\circ} \mathrm{C}$. The materials not mentioned were used as received.

\subsection{Preparation of TPU}

\subsubsection{Preparation of TPU by One-Step Polymerization Method}

PPCD, EG, DMBA, $\mathrm{FeCl}_{3}$, and DBTDL were mixed with a few solvents of THF and ether evenly, and then calculated IPDI was added and mixed. The reaction mixture was poured into the mold that had dried and preheated at $90^{\circ} \mathrm{C}$. The mixture was vacuumed until bubbles disappear, reacting at $90-130{ }^{\circ} \mathrm{C}$ for $16 \mathrm{~h}$. The as-prepared samples are 
entitled as 0-DMBA-TPU, 1-DMBA-TPU, 2-DMBA-TPU, and 3-DMBA-TPU, respectively, in which 0-DMBA-TPU excludes DMBA and DMBA content increases gradually by the serial number, whose feeding amount is shown in Table 1.

Table 1. Mechanical property and GPC data of TPU with different DMBA content.

\begin{tabular}{|c|c|c|c|c|c|c|c|}
\hline \multirow{2}{*}{ Entry } & \multirow{2}{*}{$\begin{array}{l}\text { DMBA }^{a} \\
(w t . \%)\end{array}$} & Mole Ratio & \multirow{2}{*}{$\begin{array}{c}M_{n} \\
(\mathrm{~g} / \mathrm{mol})\end{array}$} & \multirow{2}{*}{ 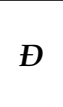 } & \multirow{2}{*}{$\begin{array}{l}\text { Tensile Strength } \\
\text { (MPa) }\end{array}$} & \multirow{2}{*}{$\begin{array}{l}\text { Tensile Modulus } \\
\text { (MPa) }\end{array}$} & \multirow{2}{*}{$\begin{array}{l}\text { Elongation } \\
\text { at Break (\%) }\end{array}$} \\
\hline & & [IPDI]:[PPCD]:[EG] + [DMBA] & & & & & \\
\hline 1 & 0.0 & $4.2: 1.0: 3.0+0.0$ & $4.1 \times 10^{4}$ & 1.9 & $6.5 \pm 0.2$ & $10.6 \pm 0.6$ & $770 \pm 22$ \\
\hline 2 & 2.3 & $4.2: 1.0: 2.5+0.5$ & $4.6 \times 10^{4}$ & 2.8 & $7.7 \pm 0.2$ & $13.4 \pm 0.3$ & $1005 \pm 55$ \\
\hline 3 & 4.5 & $4.2: 1.0: 2.0+1.0$ & $4.9 \times 10^{4}$ & 2.8 & $9.6 \pm 0.3$ & $14.7 \pm 0.6$ & $1028 \pm 19$ \\
\hline 4 & 6.7 & $4.2: 1.0: 1.5+1.5$ & $-b$ & - & $11.7 \pm 0.4$ & $16.1 \pm 0.3$ & $988 \pm 29$ \\
\hline
\end{tabular}

${ }^{a}$ DMBA weight percent; ${ }^{\mathrm{b}}$ insoluble in THF; $\mathrm{R}=1.05$; PPCD: $40 \mathrm{~g}, \mathrm{CU}=31.2 \%, \mathrm{M}_{n}=2.2 \times 10^{3} \mathrm{~g} / \mathrm{mol}, \emptyset=1.43, \mathrm{OHV}=54.0 \mathrm{mg} \mathrm{KOH} / \mathrm{g}$, in which $\mathrm{CU}$ stands for carbonate unit content; Cat.: 0.1 wt.\% DBTDL; Entry1-Entry 4 correspond to 0-DMBA-TPU, 1-DMBA-TPU, 2-DMBA-TPU, and 3-DMBA-TPU, respectively.

\subsubsection{Preparation of TPU Reinforced with $\mathrm{FeCl}_{3}$ by Pre-Polymerization Method}

The feeding amount is the same as 2-DMBA-TPU in 2.2.1 except for the amount of $\mathrm{FeCl}_{3}$. DMBA dissolved in THF and $\mathrm{FeCl}_{3}$ dissolved in ether, and then the two were mixed and stirred for complete reaction. Then the complex of DMBA and $\mathrm{FeCl}_{3}$ in the mixed solvent $\left(\mathrm{FeCl}_{3}-\mathrm{DMBA}\right)$ was obtained. PPCD, $\mathrm{FeCl}_{3}-\mathrm{DMBA}$, DBTDL was added into a three-neck flask with an electric stirrer. Then calculated IPDI was added into the flask to react for $3 \mathrm{~h}$ at $85{ }^{\circ} \mathrm{C}$ under argon atmosphere. Meanwhile, a few THF was added to reduce the viscosity. Then EG was added to the reaction mixture that had cooled to $60{ }^{\circ} \mathrm{C}$ to react for another $10 \mathrm{~min}$ after the pre-polymerization system stabilized [33]. The reaction mixture was poured into a preheating mold to continue the polymerization to obtain TPU. The mixture was vacuumed until bubbles disappear, reacting at $90-130{ }^{\circ} \mathrm{C}$ for $16 \mathrm{~h}$, whose synthesis diagram is shown in Scheme 1 and the model is shown in Figure 1. The as-prepared samples are entitled as 0/18 Fe-TPU, 1/18 Fe-TPU, 2/18 Fe-TPU, and $3 / 18 \mathrm{Fe}-\mathrm{TPU}$, in which $\mathrm{X} / \mathrm{Y}$ stands for the mole ratio of $n\left(\mathrm{FeCl}_{3}\right) / n$ (DMBA).

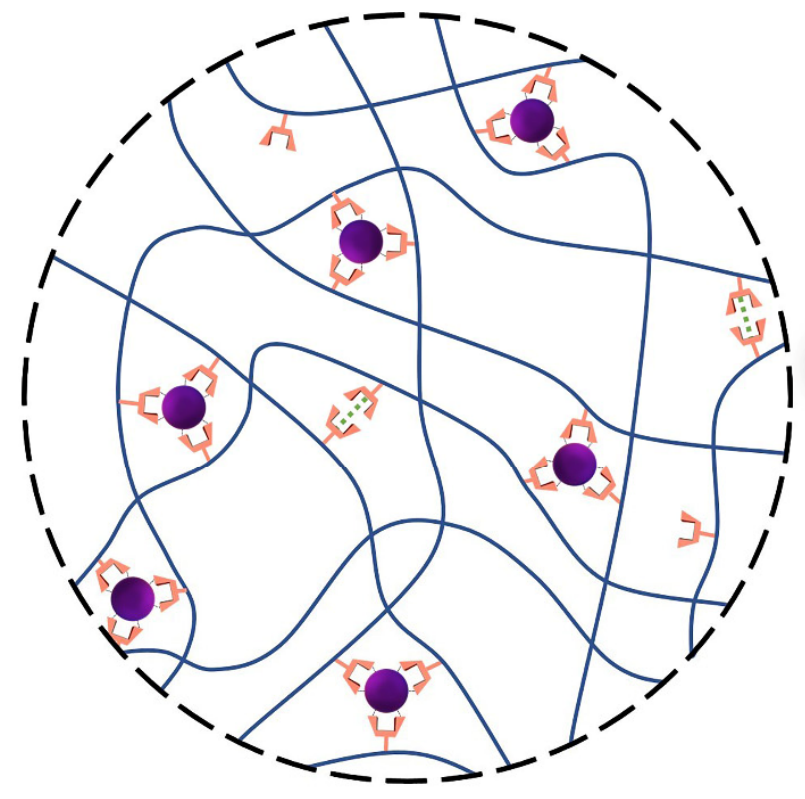

$\mathrm{Fe}^{3+} \leqslant \mathrm{COOH}$

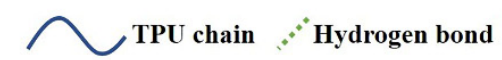

\section{Coordination enhancement}

\section{$\checkmark$ In-situ reaction}

\section{$\checkmark$ Low addition amount}

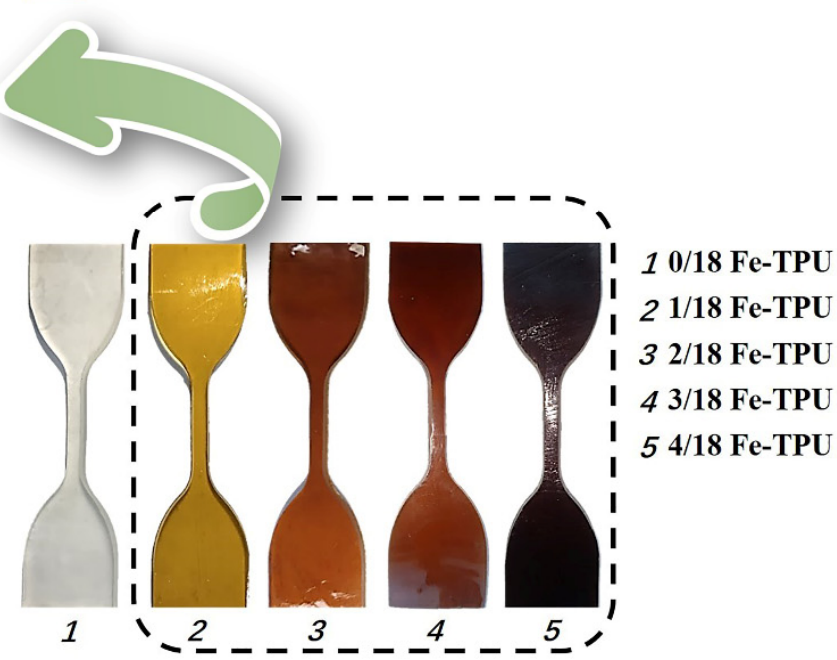

Figure 1. Model of TPU reinforced with $\mathrm{FeCl}_{3}$. 


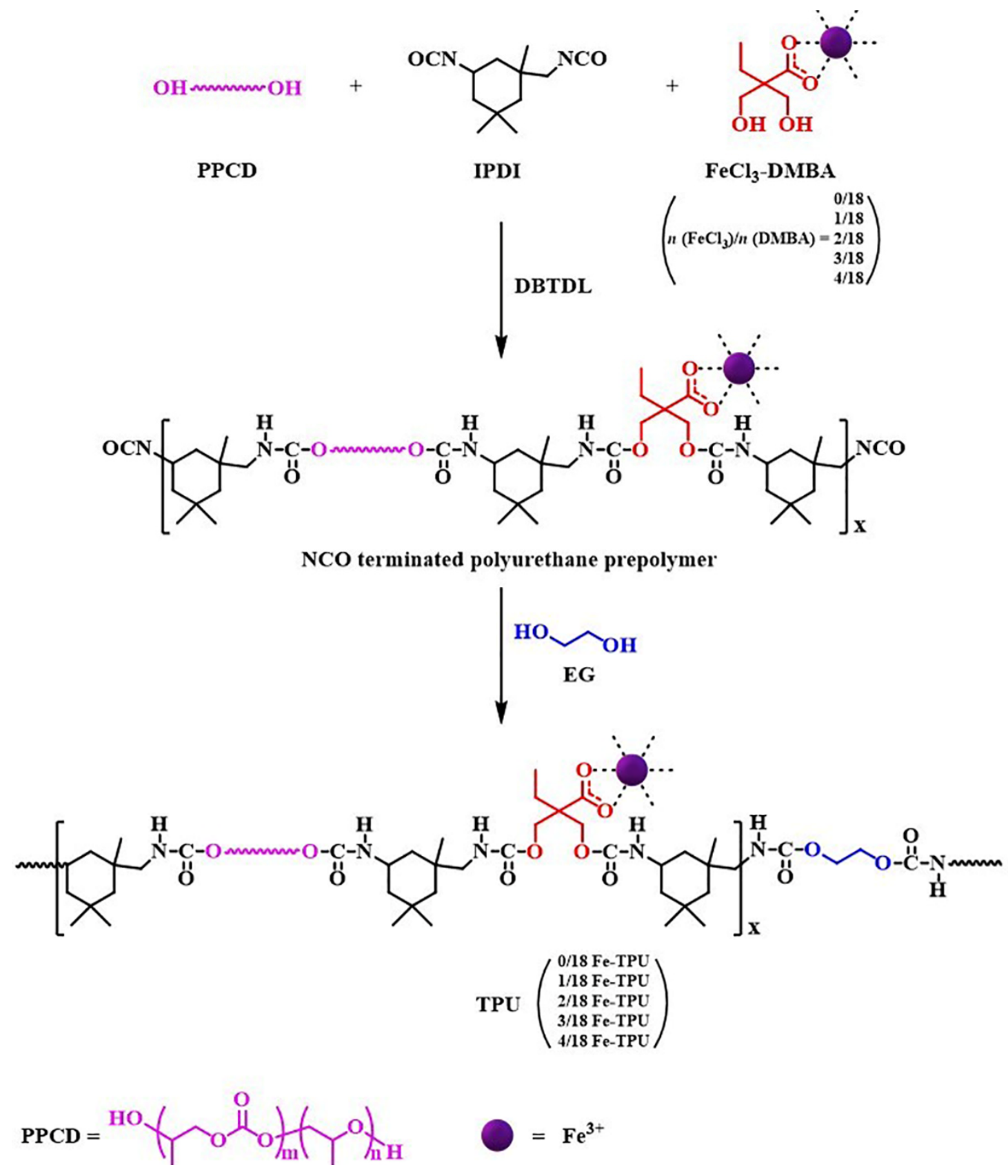

Scheme 1. Synthesis diagram of TPU.

\subsection{Analysis and Measurements}

FT-IR spectra between $400-4000 \mathrm{~cm}^{-1}$ were recorded on a Bruker VECTOR-22 spectrometer (Bruker, Karlsruhe, Germany), in which the sample was cut into small pieces to test using $\mathrm{KBr}$ pellets. ${ }^{1} \mathrm{H}$ NMR spectra were recorded on a Bruker-400 spectrometer (Bruker, Karlsruhe, Germany) at the frequency of $400 \mathrm{MHz}$. The solvent is DMSO-d6 or $\mathrm{CDCl}_{3}$ and chemical shifts are given in ppm relative to TMS. Gel permeation chromatography tests were performed on an Agilent 1260 Infinity instrument (GPC, Agilent technologies, Waldbornn, Germany), which determined number average molecular weight $\left(M_{n}\right)$ and molecular weight distribution $(Đ)$ with a refractive index detector, calibrated with polystyrene standards. The columns used were MIXED-B 10 um $300 \times 7.5 \mathrm{~mm}$ columns held at $35^{\circ} \mathrm{C}$, using THF as eluents at a flow rate of $1.0 \mathrm{~mL} / \mathrm{min}$. UV-Vis spectroscopy was performed on a Cary 60 spectrometer (UV-Vis, Agilent Technologies Ltd., Palo Alto, CA, USA). The samples were dissolved in THF to $10^{-3} \mathrm{~mol} / \mathrm{L}$, THF used as the reference 
solution. The tensile tests were performed on a CMT 1206 electronic testing machine (Nss Laboratory Equipment Ltd., Shenzhen, China). The samples were tested after placing at $25^{\circ} \mathrm{C}$ for $24 \mathrm{~h}$, which had dried at $80^{\circ} \mathrm{C}$ for $24 \mathrm{~h}$. The type is 3 in ISO $37-2017$ and the tensile rate is $100 \mathrm{~mm} / \mathrm{min}$. DMA tests were performed on a Tritec 2000 DMA equipment (Triton Technology Ltd., Nottinghamshire, UK), which determined Storage modulus $\left(E^{\prime}\right)$ and glass transition temperature $\left(T_{g}\right)$. The tests were carried out with the single cantilever mode at the frequency of $1 \mathrm{~Hz}$ and the constant applied strain of $0.1 \%$ within $-50-60{ }^{\circ} \mathrm{C}$ at the heating rate of $3{ }^{\circ} \mathrm{C} / \mathrm{min}$ under nitrogen atmosphere, whose size of the sample is $40 \mathrm{~mm} \times 7 \mathrm{~mm} \times 2 \mathrm{~mm}$. X-ray diffraction tests were performed on a MiniFlex600 diffractometer (XRD, Rigaku Ltd., Tokyo, Japan). The tests were carried out on the reflection mode at the scanning speed of $4^{\circ} / \mathrm{min}$ within the range of $5-80^{\circ}$ at the step size of $0.02^{\circ}$. Differential scanning calorimetric tests were performed on a Dimond DSC equipment (DSC, PerkinElmer, Waltham, MA, USA) and an empty aluminum crucible was used as the reference. The samples were tested at a rate of $10^{\circ} \mathrm{C} / \mathrm{min}$ over the range of $-50-200{ }^{\circ} \mathrm{C}$ in the nitrogen atmosphere after removing the thermal history. TGA tests were recorded on an SDT-Q600 system (TA Instruments, Newcastle, WY, USA) and an empty alumina crucible was used as the reference. The tests were carried out within the range from 40 to $600{ }^{\circ} \mathrm{C}$ at a heating rate of $10{ }^{\circ} \mathrm{C} / \mathrm{min}$ under a nitrogen atmosphere at a flow rate of $100 \mathrm{~mL} / \mathrm{min}$.

\section{Results and Discussion}

\subsection{Chemical Structure of TPU}

The chemical structure of TPU is subjected to FT-IR and ${ }^{1} \mathrm{H}$ NMR analysis as shown in Figures 2 and 3. FT-IR spectra correspond to PPCD, 0/18 Fe-TPU, 1/18 Fe-TPU, and $3 / 18 \mathrm{Fe}$-TPU respectively.

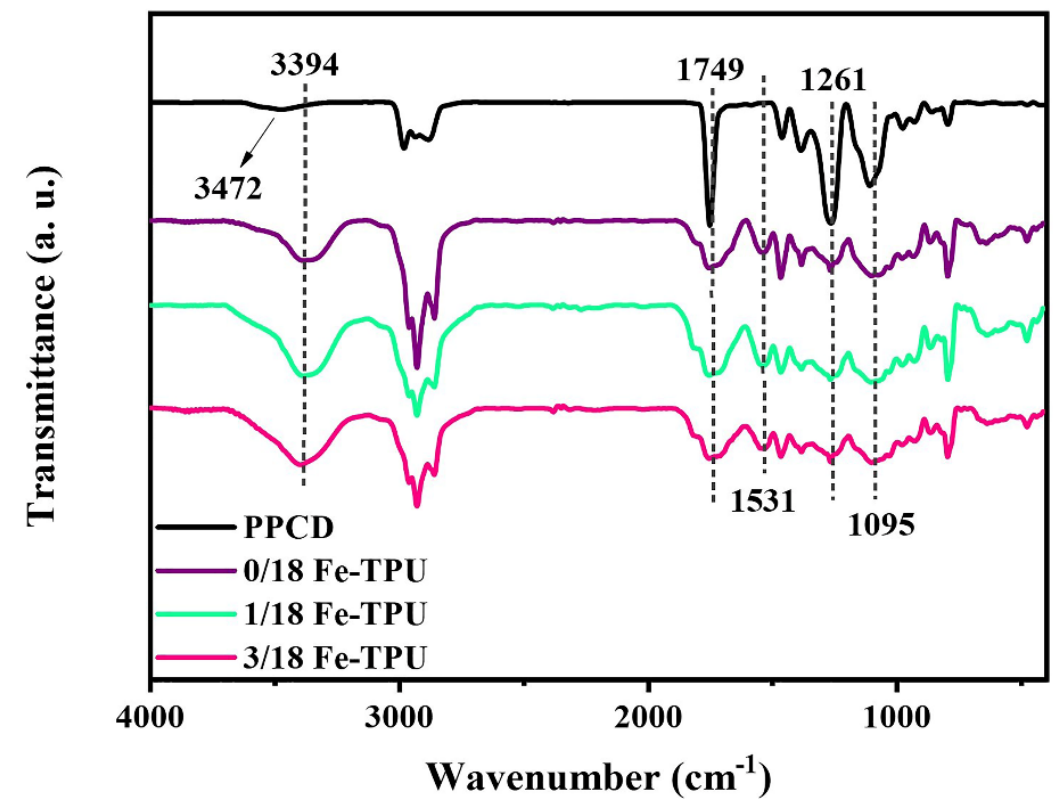

Figure 2. FT-IR spectra of TPU.

In PPCD, the absorption peak at $1749 \mathrm{~cm}^{-1}$ is assigned to stretching vibrations of $\mathrm{C}=\mathrm{O}$ in the carbonate group. The absorption peaks at $1261 \mathrm{~cm}^{-1}, 1095 \mathrm{~cm}^{-1}$ are ascribed to $\mathrm{C}-\mathrm{O}$ of the carbonate group and $\mathrm{C}-\mathrm{O}$ of the ether linkage $[10,11]$, which also appears in spectra of TPU. The absorption peak near $3394 \mathrm{~cm}^{-1}$ should be assigned to stretching vibrations of $\mathrm{N}-\mathrm{H}$, which are located within the hard segment domains. The absorption peak near $1749 \mathrm{~cm}^{-1}$ is attributed to $\mathrm{C}=\mathrm{O}$ of the carbamate group, and the absorption peak at $1531 \mathrm{~cm}^{-1}$ is the characteristic absorption peak of C-N-H [34-36]. Therefore, the 
presence of the absorption peaks at $3394 \mathrm{~cm}^{-1}, 1749 \mathrm{~cm}^{-1}$, and $1531 \mathrm{~cm}^{-1}$ confirmed that TPU is successfully prepared [10].

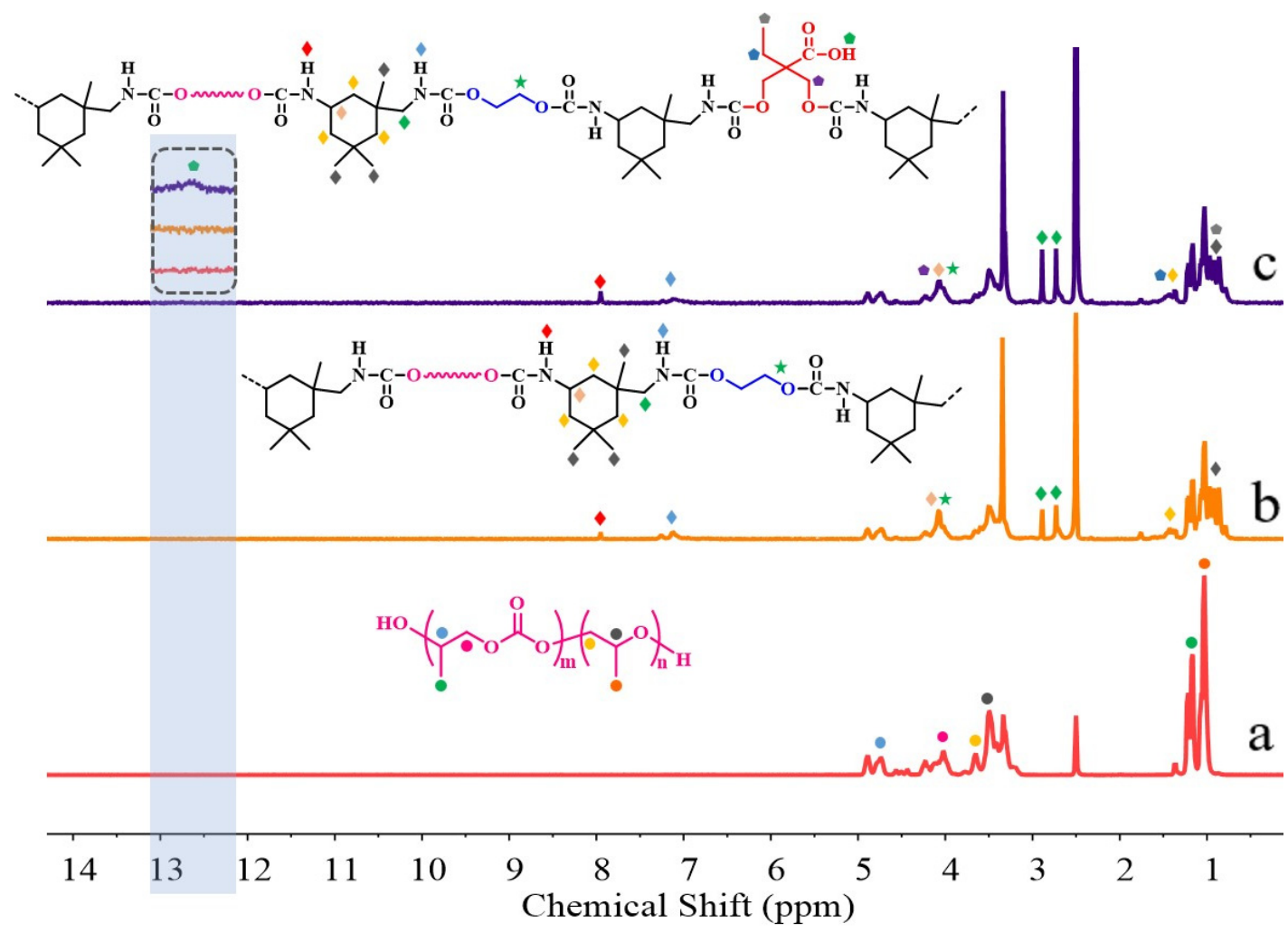

Figure 3. ${ }^{1} \mathrm{H}$ NMR spectra of (a) PPCD, (b) 0-DMBA-TPU, and (c) 2-DMBA-TPU.

Meanwhile, ${ }^{1} \mathrm{H}$ NMR spectra of PPCD and TPU prepared by pre-polymerization were performed, using DMSO- $d 6$ as the solvent. Figure $3 a-c$ correspond to PPCD, 0-DMBA-TPU, and 2-DMBA-TPU respectively.

The assignment of the ${ }^{1} \mathrm{H}$ NMR absorption peak is shown in Figure $3[11,28,34]$. The peaks within 4.8-5.2 ppm and 4.0-4.3 ppm in Figure 3a are attributed to $\mathrm{CH}$ and $\mathrm{CH}_{2}$, which adjoin to the polycarbonate segment. The peaks within 3.2-4.0 ppm are assigned to $\mathrm{CH}$ and $\mathrm{CH}_{2}$, which connect to the ether linkage. The peaks in PPCD are not subdivided in Figure $3 \mathrm{~b}, \mathrm{c}$. The peaks at $7.1 \mathrm{ppm}$ and $8.0 \mathrm{ppm}$ are attributed to $\mathrm{N}-\mathrm{H}$ in the carbamate group. The assigned peaks in Figure $3 b, c$ coincide with ${ }^{1} \mathrm{H}$ NMR spectrum of typical PEC-based polyurethane $[10,11]$, indicating that TPU is successfully prepared. The active hydrogen peak of the carboxyl group at $12.8 \mathrm{ppm}$ in 2-DMBA-TPU is found through local amplification between 12.2-13.2 ppm, which is absent in Figure $3 a, b$ and further confirms that the carboxyl groups have been introduced via DMBA chain extender.

\subsection{Effect of DMBA on Mechanical Properties of TPU}

The introduced carboxyl groups can form hydrogen bonds with themselves or carbamate, affecting the performance of TPU [23]. More importantly, the amount of DMBA determines the number of the carboxyl groups that interact with $\mathrm{FeCl}_{3}$, so it is important and reasonable to study the effect of DMBA content on the mechanical properties of TPU. Therefore, a series of TPUs with different DMBA content were synthesized by a relatively simple one-step polymerization method at $\mathrm{R}=1.05(\mathrm{R}=[-\mathrm{NCO}] /[-\mathrm{OH}])[37]$, and the results are shown in Table 1 and Figure 4. 

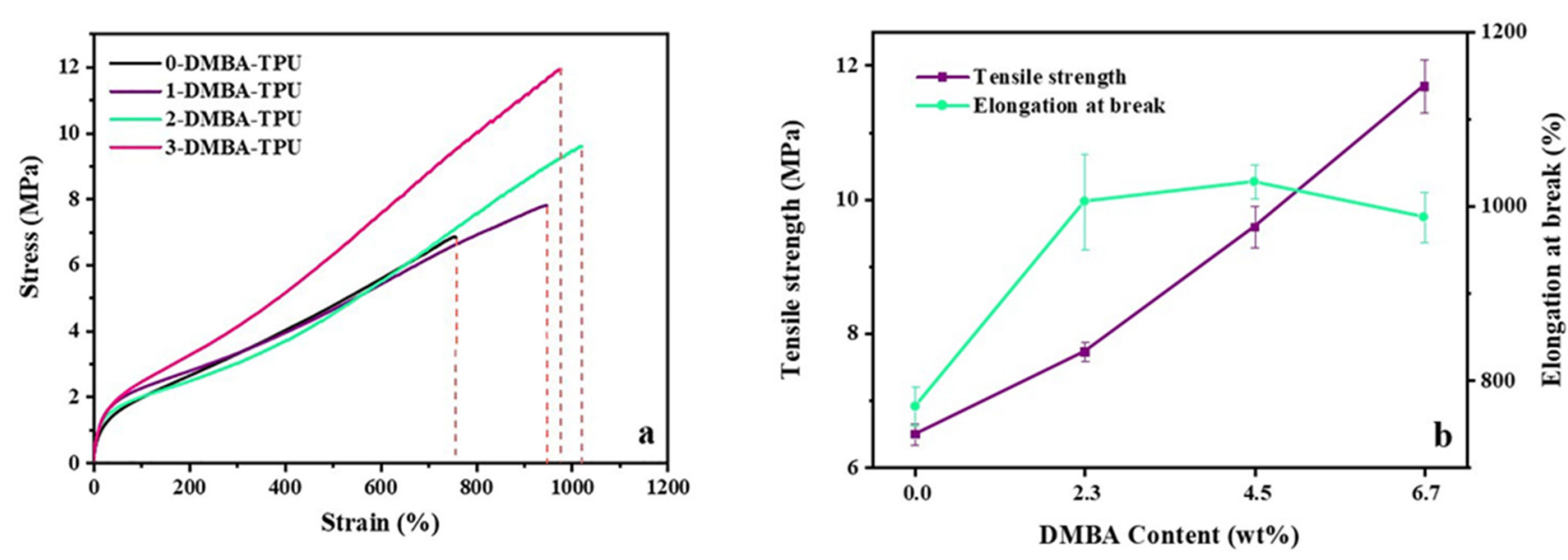

Figure 4. (a) Tensile stress-strain curves, (b) mechanical performances of TPU with different DMBA content.

As shown in Table 1 and Figure 4, the tensile strength of TPU gradually increases with the increasing DMBA content. The tensile strength of 0-DMBA-TPU is $6.5 \mathrm{MPa}$, which increases to the maximum of $11.7 \mathrm{MPa}$ gradually. The elongation at break of 0-DMBA-TPU is $770 \%$. After the introduction of DMBA, the elongation at break all increase to about $1000 \%$. The larger ethyl side chains of DMBA reduces chain mobility and the chains are hard to align to recrystallize, which leads to better mutual solubility between soft segment and hard segment and then results in higher mechanical properties [27]. To sum up, it shows that DMBA as the chain extender can enhance both strength and toughness to a certain extent. GPC tests show that $M_{n}$ of TPU increases with the increasing DMBA content. The reason may be that the molecular weight of DMBA is larger than that of EG, whose GPC curves are shown in Figure S3.

\subsection{Effect of $\mathrm{FeCl}_{3}$ on Polymerization Process of TPU}

The experimental results show that direct addition of $\mathrm{FeCl}_{3}$ will unstabilize the prepolymerization system and lead to such adverse phenomenon as gelation and difficult molding. It is a valid strategy that $\mathrm{FeCl}_{3}$ coordinates with DMBA to minimize the adverse effect. Aiming to study the effect of $\mathrm{FeCl}_{3}$ on polymerization process in pre-polymerization method with pre-coordination of $\mathrm{FeCl}_{3}$ and DMBA, the tests of UV-Vis, FT-IR spectra, GPC, and ${ }^{1} \mathrm{H}$ NMR were used to characterize the coordination effect of $\mathrm{FeCl}_{3}-\mathrm{DMBA}$, and prepolymer respectively. UV-Vis spectra of DMBA, $\mathrm{FeCl}_{3}$, and $\mathrm{FeCl}_{3}-\mathrm{DMBA}$ are shown in Figure 5a. The concentration of DMBA is $10^{-3} \mathrm{~mol} / \mathrm{L}\left(n\left(\mathrm{FeCl}_{3}\right) / n(\mathrm{DMBA})=3 / 18\right)$ and the reference solvent is the mixture of THF and ether $(v(\mathrm{THF}) / v($ ether $)=1 / 1)$. DMBA has almost no absorption and the absorption peaks of $\mathrm{FeCl}_{3}-\mathrm{DMBA}$ are different from that of $\mathrm{FeCl}_{3}$ significantly [38]. Furthermore, the DMBA solution is colorless and transparent, the $\mathrm{FeCl}_{3}$ solution is yellow-green, and the $\mathrm{FeCl}_{3}$-DMBA solution is orange-red, whose color-changing is caused by the coordination effect between the carboxyl groups and $\mathrm{FeCl}_{3}$. The results show that there is an obvious coordination effect between DMBA and $\mathrm{FeCl}_{3}$.

The prepolymer of $0 / 18 \mathrm{Fe}-\mathrm{TPU}(0 / 18 \mathrm{Fe}-\mathrm{TPU}-\mathrm{Prepolymer})$ and $3 / 18 \mathrm{Fe}-\mathrm{TPU}(3 / 18$ Fe-TPU-Prepolymer) were simultaneously sampled for tests of FT-IR spectra, GPC, and ${ }^{1} \mathrm{H}$ NMR to study the effect of $\mathrm{FeCl}_{3}$ on the prepolymer, and the result are shown in Figure $5 b, c$ and Figure $S 2$ respectively.

As shown in Figure 5b, FT-IR spectra of 0/18 Fe-TPU-Prepolymer and 3/18 Fe-TPUPrepolymer coincide, which are similar to TPU in Figure 2 except for the intense -NCO absorption peak. The similar phenomena happen in the testing of GPC and ${ }^{1} \mathrm{H}$ NMR, in which the testing results of $0 / 18$ Fe-TPU-Prepolymer and 3/18 Fe-TPU-Prepolymer are similar in Figure 5c and Figure S2 respectively. The results confirm that the introduction of $\mathrm{FeCl}_{3}$ has no significant effect on prepolymer and then the polymerization process. Figure $5 \mathrm{~d}$ shows the physical pictures of TPU, in which the color of the sample without 
$\mathrm{FeCl}_{3}$ is transparent and gradually deepens to dark brown with the increasing amount of $\mathrm{FeCl}_{3}$.
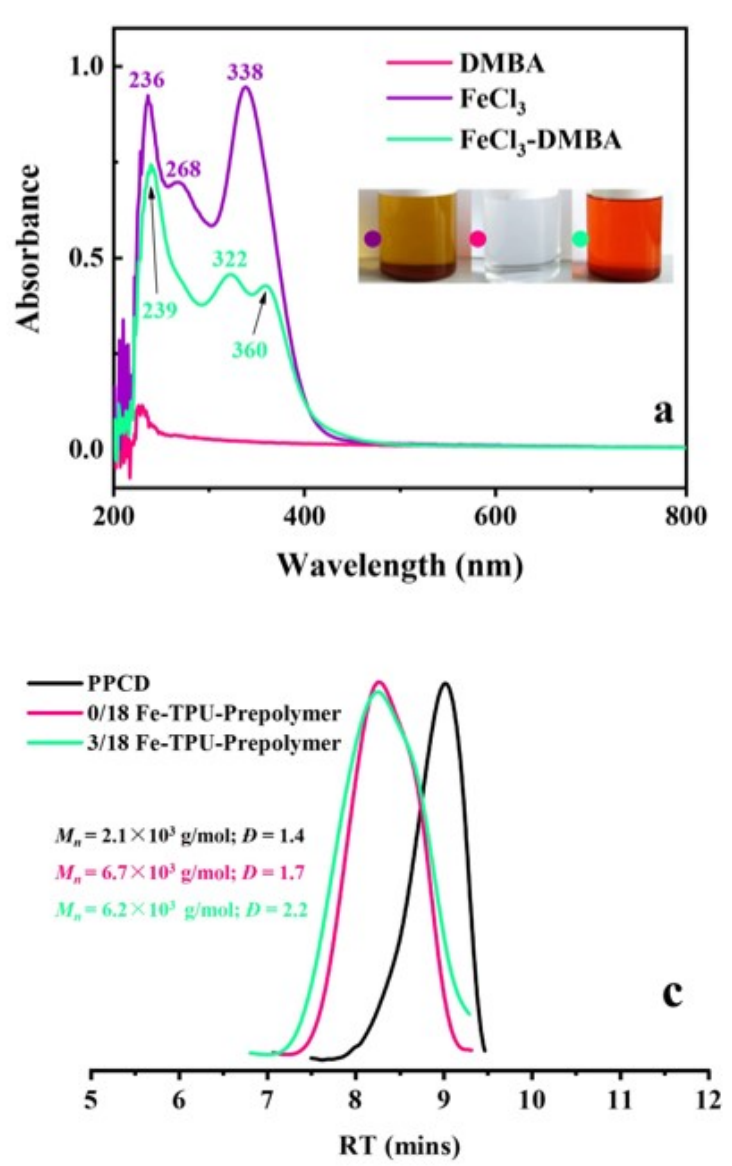
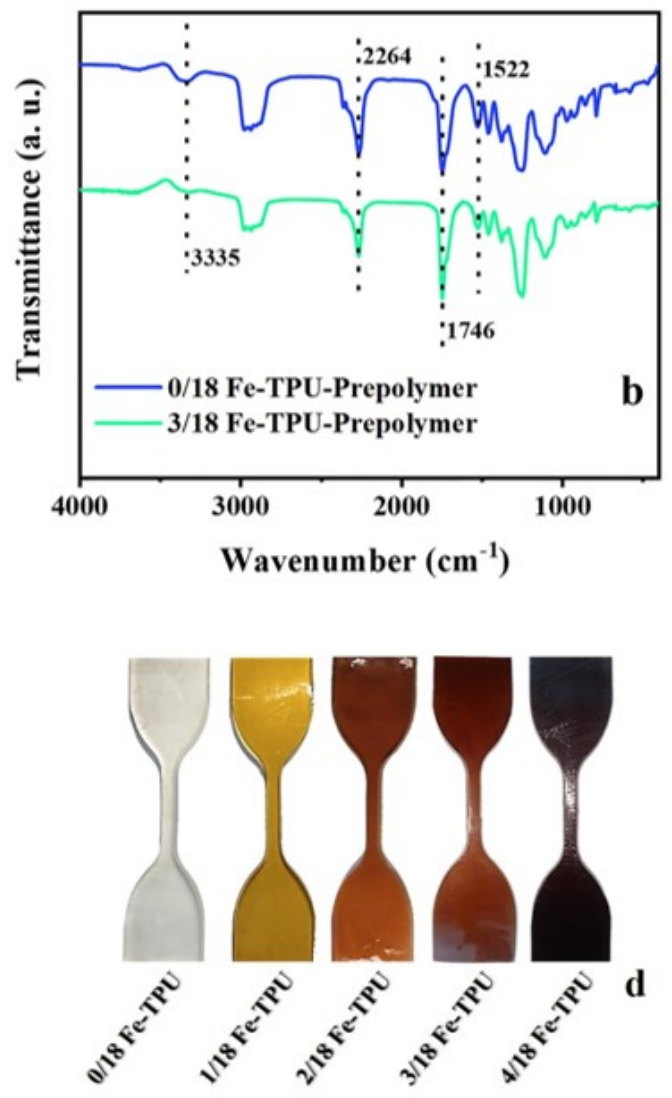

Figure 5. (a) UV-Vis spectra of DMBA, $\mathrm{FeCl}_{3}$, and $\mathrm{FeCl}_{3}-\mathrm{DMBA}$; (b) FT-IR spectra of the prepolymer; (c) GPC curves of PPCD and the prepolymer; (d) physical pictures of TPU.

\subsection{Mechanical Properties of TPU Reinforced with $\mathrm{FeCl}_{3}$}

The mechanical properties of TPU reinforced with $\mathrm{FeCl}_{3}$ are shown in Figure 6 and Table 2, whose addition amounts of $\mathrm{FeCl}_{3}$ correspond to 0.0 wt.\%, 0.3 wt.\%, 0.5 wt.\%, $0.8 \mathrm{wt} . \%$, and $1.0 \mathrm{wt} . \%$ from Entry 1 to Entry 5 respectively. Generally, DMBA in Table 2 is potential to coordinate with more $\mathrm{FeCl}_{3}$. Because the viscosity of the reaction system gradually increases with the increasing addition of $\mathrm{FeCl}_{3}$, the processing becomes difficult, for which the value of $n\left(\mathrm{FeCl}_{3}\right) / n$ (DMBA) up to $4 / 18$ to the maximum. The tensile strength and modulus gradually increase with the increasing addition of $\mathrm{FeCl}_{3}$. The tensile strength of $0 / 18 \mathrm{Fe}-\mathrm{TPU}$ is $10.3 \mathrm{MPa}$, which increases to the maximum of $17.8 \mathrm{MPa}$ with an increasing rate of $72.8 \%$. The tensile modulus also increases gradually with the increasing addition of $\mathrm{FeCl}_{3}$, whose value increases from $14.8 \mathrm{MPa}$ to the maximum of $93.9 \mathrm{MPa}$. On the other hand, the elongation at break decreases as the addition amount of $\mathrm{FeCl}_{3}$ increases. The reason for this phenomenon is that the density of crosslinks constructed by the carboxyl groups and $\mathrm{FeCl}_{3}$ increase, thus resulting in higher tensile strength, modulus, but lower elongation at break $[23,25]$. 
Table 2. Mechanical property of TPU reinforced with $\mathrm{FeCl}_{3}$.

\begin{tabular}{|c|c|c|c|c|c|c|}
\hline Entry & Sample ${ }^{a}$ & $\begin{array}{c}n\left(\mathrm{FeCl}_{3}\right) / n(\mathrm{DMBA}) \\
(\mathrm{mol} / \mathrm{mol})\end{array}$ & $\begin{array}{c}\text { Tensile Strength } \\
\text { (MPa) }\end{array}$ & $\begin{array}{l}\text { Tensile Modulus } \\
\text { (MPa) }\end{array}$ & $\begin{array}{c}\text { Elongation } \\
\text { at Break (\%) }\end{array}$ & $\begin{array}{l}\text { Hardness } \\
\text { (Shore A) }\end{array}$ \\
\hline 1 & 0/18 Fe-TPU & $0 / 18$ & $10.3 \pm 0.5$ & $14.8 \pm 1.1$ & $912 \pm 39$ & 45 \\
\hline 2 & 1/18 Fe-TPU & $1 / 18$ & $11.9 \pm 0.3$ & $18.7 \pm 1.1$ & $802 \pm 30$ & 43 \\
\hline 3 & $2 / 18 \mathrm{Fe}-\mathrm{TPU}$ & $2 / 18$ & $13.3 \pm 0.4$ & $35.8 \pm 1.5$ & $768 \pm 19$ & 46 \\
\hline 4 & $3 / 18 \mathrm{Fe}-\mathrm{TPU}$ & $3 / 18$ & $14.6 \pm 0.8$ & $58.6 \pm 2.3$ & $722 \pm 19$ & 45 \\
\hline 5 & 4/18 Fe-TPU & $4 / 18$ & $17.8 \pm 0.5$ & $93.9 \pm 2.6$ & $535 \pm 34$ & 47 \\
\hline
\end{tabular}

a The feeding amount is the same as that of 2-DMBA-TPU; ${ }^{\mathrm{b}}$ the amount of $\mathrm{FeCl}_{3}$ is denoted as $n\left(\mathrm{FeCl}_{3}\right) / n(\mathrm{DMBA}) ; \mathrm{R}=1.05 ; \mathrm{PPCD}: 40 \mathrm{~g}$, $C U=31.2 \%, M_{n}=2.2 \times 10^{3} \mathrm{~g} / \mathrm{mol}, \oplus=1.43, O H V=54.0 \mathrm{mg} \mathrm{KOH} / \mathrm{g}$; Cat.: 0.1 wt. $\%$ DBTDL.
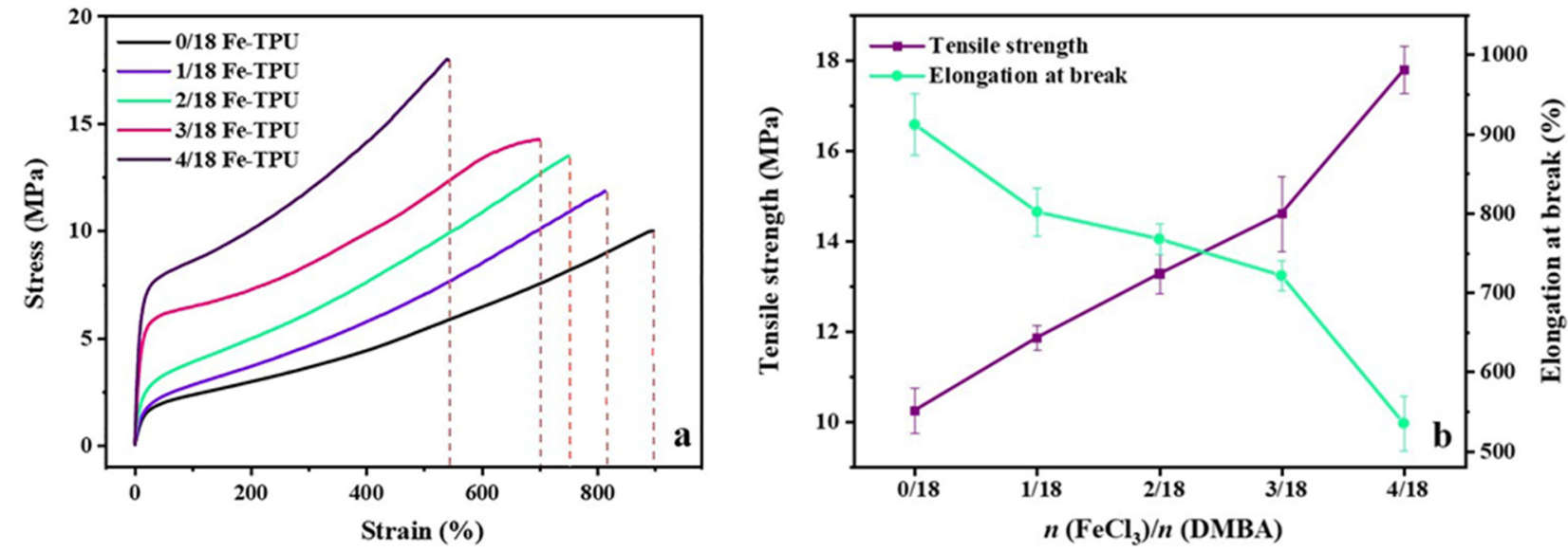

Figure 6. (a) Tensile stress-strain curves, (b) mechanical performances of TPU reinforced with $\mathrm{FeCl}_{3}$.

\subsection{DMA Tests of TPU Reinforced with $\mathrm{FeCl}_{3}$}

To study $E^{\prime}$ and $T_{g}$ of TPU reinforced by $\mathrm{FeCl}_{3}$, DMA tests were conducted, and the results are shown in Figure 7. It is obvious that $E^{\prime}$ of TPU gradually increases with the increasing addition of $\mathrm{FeCl}_{3}$, which reflects that the motility of the chains in TPU gradually decreases with increasing density of coordination cross-linking. The restricted chain mobility means the chains are more rigid and less easy to move, which results in a higher $E^{\prime}[24,39]$.
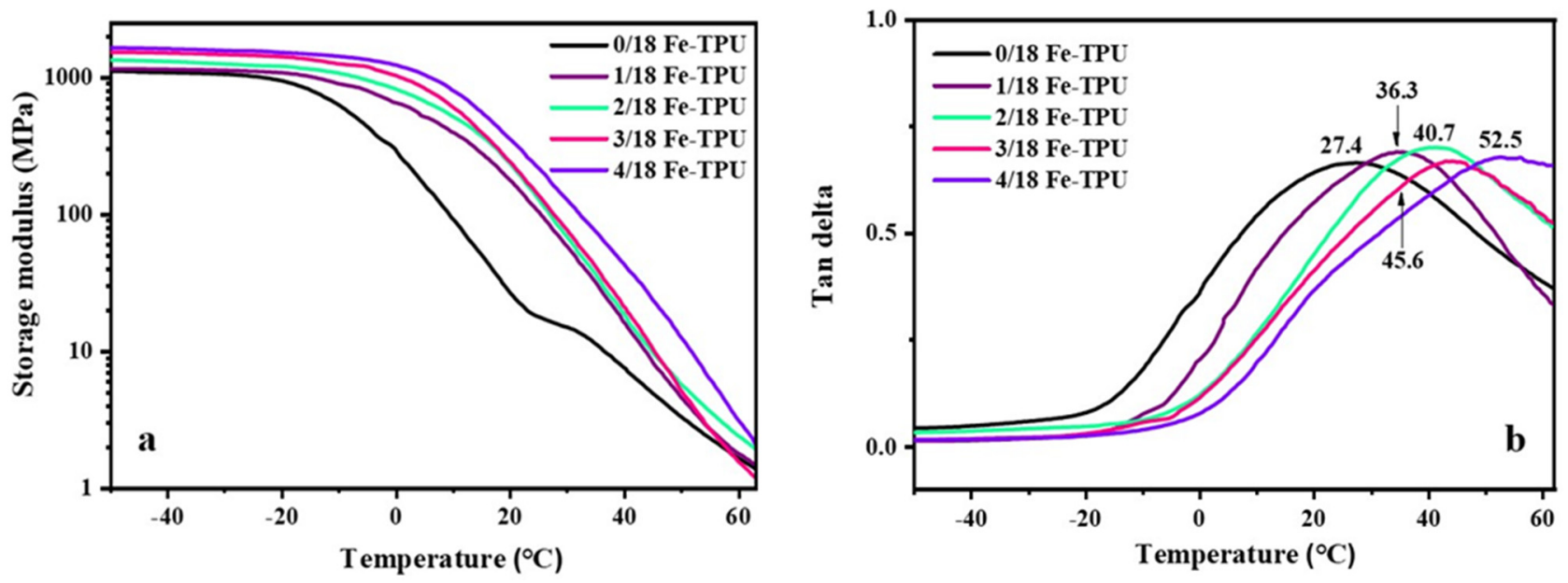

Figure 7. (a) Storage modulus, (b) tan delta of TPU reinforced with $\mathrm{FeCl}_{3}$.

$T_{g}$ determined by DMA gradually moves to high temperature with the increasing addition of $\mathrm{FeCl}_{3} . \mathrm{T}_{g}$ of $0 / 18 \mathrm{Fe}$-TPU is $27.4{ }^{\circ} \mathrm{C}$, and that of $4 / 18 \mathrm{Fe}$-TPU rises to the maximum of $52.5^{\circ} \mathrm{C}$. The reason is that the density of coordination cross-linking increases, 
which restricts the motility of the TPU chains, so $T_{g}$ gradually moves toward a high temperature with the increasing addition of $\mathrm{FeCl}_{3}$.

\subsection{Crystallization Performance of TPU Reinforced with $\mathrm{FeCl}_{3}$}

To study the crystallization performance of TPU reinforced by $\mathrm{FeCl}_{3}, \mathrm{XRD}$ tests of Entry 1-Entry 5 in Table 2 were performed and the results were shown in Figure 8. It is obvious that the spectra appear typical diffuse scattering peak at $2 \theta=19^{\circ}$, which means the crystallinity of relatively ordered hard segments domains in polymers [5,40]. Then, it confirms that the TPU reinforced by $\mathrm{FeCl}_{3}$ or not are amorphous polymers, and also it is mainly the reason why the melting peak of TPU is not observed in DSC tests in Figure S4 and Table S2.

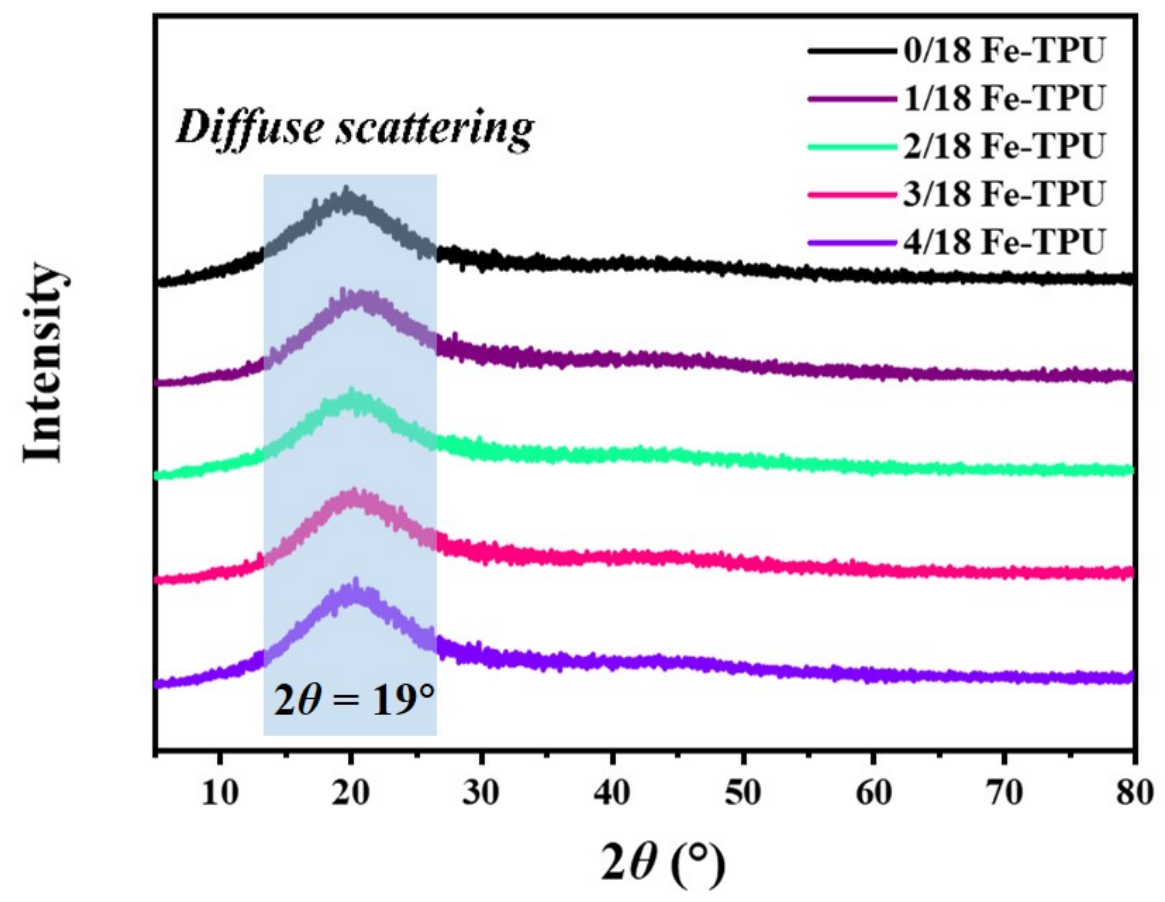

Figure 8. XRD spectra of TPU reinforced with $\mathrm{FeCl}_{3}$.

\subsection{Thermal Stability of TPU Reinforced with $\mathrm{FeCl}_{3}$}

To study the thermal stability of TPU reinforced with $\mathrm{FeCl}_{3}$, TGA tests Entry 1-Entry 5 in Table 2 were conducted and the results are shown in Figure 9 and Table 3. $T_{5 \%}$ gradually decreases with the increasing addition of $\mathrm{FeCl}_{3}$, which is usually used as the onset decomposition temperature [27]. $T_{5 \%}$ of $0 / 18 \mathrm{Fe}$-TPU is $266.4{ }^{\circ} \mathrm{C}$ and $T_{5 \%}$ of $4 / 18 \mathrm{Fe}$-TPU decreases to $243.8{ }^{\circ} \mathrm{C}$ in Figure $9 \mathrm{a}$ and Table 3. $T_{10 \%}$ and $T_{\max }$ also decrease similarly, demonstrating the thermal stability of TPU decreases with the introduction of $\mathrm{FeCl}_{3}$. On the one hand, the coordination bonds rupture at a high temperature and the ferric compound evenly distributes in TPU, which is equivalent to a physical filler that weakens the interaction, resulting in the decrease in thermal stability [41]. On the other hand, many researchers have widely revealed that the interaction of such Lewis acid as transition metals in the polymer can boost thermal degradation of the organic matrix, leading to adverse effects [42-44]. 

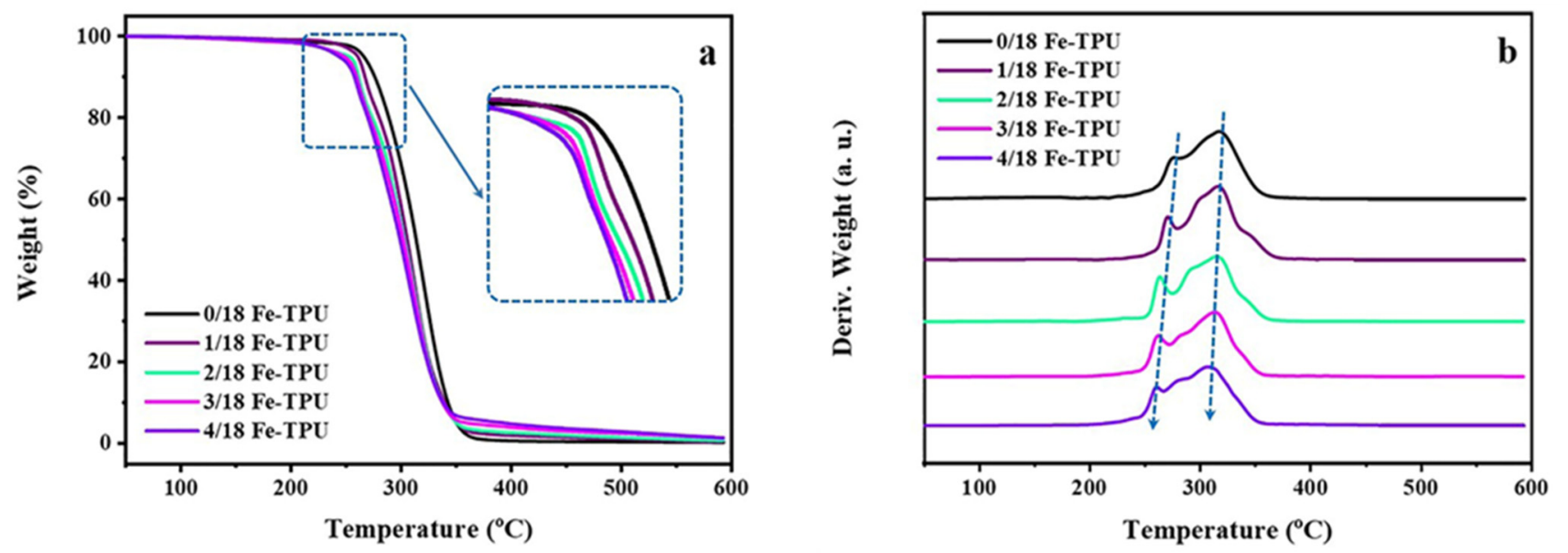

Figure 9. (a) TG curves, (b) DTG curves of TPU reinforced with $\mathrm{FeCl}_{3}$.

Table 3. TGA data of TPU reinforced with $\mathrm{FeCl}_{3}$.

\begin{tabular}{ccccc}
\hline Entry & Sample & $\boldsymbol{T}_{\mathbf{5} \%}\left({ }^{\circ} \mathbf{C}\right)^{\mathbf{a}}$ & $\mathbf{T}_{\mathbf{1 0} \%}\left({ }^{\circ} \mathbf{C}\right)^{\mathbf{b}}$ & $\boldsymbol{T}_{\max }\left({ }^{\circ} \mathbf{C}\right)^{\mathbf{c}}$ \\
\hline 1 & $0 / 18$ Fe-TPU & 266.4 & 276.5 & 317.9 \\
2 & $1 / 18$ Fe-TPU & 261.0 & 267.6 & 316.9 \\
3 & $2 / 18$ Fe-TPU & 253.1 & 261.9 & 315.9 \\
4 & $3 / 18$ Fe-TPU & 248.6 & 260.0 & 313.9 \\
5 & $4 / 18$ Fe-TPU & 243.8 & 257.9 & 309.5 \\
\hline
\end{tabular}

${ }^{\mathrm{a}} T_{5 \%}: 5 \mathrm{wt} . \%$ loss temperature, the onset decomposition temperature; ${ }^{\mathrm{b}} T_{10 \%}: 10 \mathrm{wt} . \%$ loss temperature; ${ }^{\mathrm{c}} T_{\max }$ maximum rate of weight loss temperature.

As shown in Figure 9b. Two thermal decomposition peaks can observe through DTG curves. The peak within $260-290{ }^{\circ} \mathrm{C}$ corresponds to the hard segment, and the other within $290-320^{\circ} \mathrm{C}$ corresponds to the soft segment $[11,27]$. Both gradually move to lower temperatures with the increasing addition of $\mathrm{FeCl}_{3}$ for the same reason as $T_{g}$ curves.

\section{Conclusions}

In summary, carbon dioxide PEC polyols-based TPU reinforced with $\mathrm{FeCl}_{3}$ was successfully prepared, which was tested and characterized using different approaches, including FT-IR spectroscopy, ${ }^{1} \mathrm{H}-\mathrm{NMR}$, GPC, UV-Vis, tensile testing, XRD, DMA, and TGA. By exploring the adding method of $\mathrm{FeCl}_{3}$, it is found that TPU prepared through $\mathrm{FeCl}_{3}$-DMBA possesses well-comprehensive properties. With the increasing addition of $\mathrm{FeCl}_{3}$, the tensile strength and modulus of TPU increased, but the elongation at break decreased. DMA tests show that the $T_{g}$ moves to a high temperature gradually along with an increasing addition of $\mathrm{FeCl}_{3}$. XRD tests indicate that TPUs reinforced with $\mathrm{FeCl}_{3}$ or not are amorphous polymers. TGA tests show that thermal stability decreases gradually with increasing addition of $\mathrm{FeCl}_{3}$. This synthesis strategy has the advantages of low iron addition, in-situ reaction, and no separation of intermediate products. Compared with the traditional route of first obtaining polymer and then dissolving to coordinate with metal centers, this work provides a more effective strategy for large-scale industrial applications, that is, adding $\mathrm{FeCl}_{3}$ in the preparation stage and directly obtaining TPU with coordination enhancement.

Supplementary Materials: The following are available online at https: / www.mdpi.com/article / 10.3390/polym13162765/s1, Figure S1: 1H NMR spectrum of PPCD, Figure S2: 1H NMR spectra of (a) 0/18 Fe-TPU-Prepolymer and (b) 3/18 Fe-TPU-Prepolymer, Figure S3: GPC curves of TPU with different DMBA contents, Figure S4: DSC curves of TPU reinforced with FeCl3, Table S1: Data summary of PPCD, Table S2: DSC data of TPU reinforced with $\mathrm{FeCl}_{3}$. 
Author Contributions: Experiment designing, data analyzing, data graphing, and original draft writing, G.G.; methodology, J.D.; draft reviewing and editing, Z.D. and B.L.; project administration, B.L. All authors have read and agreed to the published version of the manuscript.

Funding: This research was funded by the National Natural Scientific Foundation of China (No. 51873055) and the Natural Scientific Foundation of Hebei Province (No. B2018202112).

Institutional Review Board Statement: Not applicable.

Informed Consent Statement: Not applicable.

Data Availability Statement: The data presented in this study are available.

Conflicts of Interest: The authors declare no conflict of interest.

\section{References}

1. Maisonneuve, L.; Lebarbé, T.; Grau, E.; Cramail, H. Structure-properties relationship of fatty acid-based thermoplastics as synthetic polymer mimics. Polym. Chem. 2013, 4, 5472-5517. [CrossRef]

2. Yilgör, I.; Yilgor, E.; Wilkes, G.L. Critical parameters in designing segmented polyurethanes and their effect on morphology and properties: A comprehensive review. Polymer 2015, 58, A1-A36. [CrossRef]

3. Chattopadhyay, D.; Raju, K. Structural engineering of polyurethane coatings for high performance applications. Prog. Polym. Sci. 2007, 32, 352-418. [CrossRef]

4. Xu, C.-A.; Chen, G.; Tan, Z.; Hu, Z.; Qu, Z.; Zhang, Q.; Lu, M.; Wu, K.; Lu, M.; Liang, L. Evaluation of cytotoxicity in vitro and properties of polysiloxane-based polyurethane/lignin elastomers. React. Funct. Polym. 2020, 149, 104514. [CrossRef]

5. Yu, X.; Xiong, Y.; Zhou, C.; Li, G.; Ren, S.; Li, Z.; Tang, H. Polyurethane with tris(trimethylsiloxy)silyl propyl as the side chains: Synthesis and properties. Prog. Org. Coat. 2020, 142, 105605. [CrossRef]

6. $\quad$ Luong, N.D.; Sinh, L.H.; Minna, M.; Jurgen, W.; Torsten, W.; Matthias, S.; Jukka, S. Synthesis and characterization of castor oil-segmented thermoplastic polyurethane with controlled mechanical properties. Eur. Polym. J. 2016, 81, $129-137$.

7. Nofar, M.; Bati, B.; Kucik, E.B.; Jalali, A. Effect of soft segment molecular weight on the microcellular foaming behavior of TPU using supercritical $\mathrm{CO}_{2}$. J. Supercrit. Fluid. 2020, 160, 104816. [CrossRef]

8. Krol, P. Synthesis methods, chemical structures and phase structures of linear polyurethanes. Properties and applications of linear polyurethanes in polyurethane elastomers, copolymers and ionomers. Prog. Mater. Sci. 2007, 52, 915-1015. [CrossRef]

9. Qin, Y.S.; Wang, X.H. Carbon dioxide-based copolymers: Environmental benefits of PPC, an industrially viable catalyst. Biotechnol. J. 2010, 5, 1164-1180. [CrossRef]

10. Wang, J.; Zhang, H.; Miao, Y.; Qiao, L.; Wang, X.; Wang, F. Waterborne polyurethanes from $\mathrm{CO}_{2}$ based polyols with comprehensive hydrolysis/oxidation resistance. Green Chem. 2015, 18, 524-530. [CrossRef]

11. Ma, K.; Bai, Q.; Zhang, L.; Liu, B. Synthesis of flame-retarding oligo(carbonate-ether) diols via double metal cyanide complexcatalyzed copolymerization of $\mathrm{PO}$ and $\mathrm{CO}_{2}$ using bisphenol A as a chain transfer agent. RSC Adv. 2016, 6, 48405-48410. [CrossRef]

12. Gunatillake, P.A.; Meijs, G.F.; Rizzardo, E.; Chatelier, R.C.; McCarthy, S.J.; Brandwood, A.; Schindhelm, K. Polyurethane elastomers based on novel polyether macrodiols and MDI: Synthesis, mechanical properties, and resistance to hydrolysis and oxidation. J. Appl. Polym. Sci. 1992, 46, 319-328. [CrossRef]

13. Brown, D.W.; Lowry, R.E.; Smith, L.E. Kinetics of Hydrolytic Aging of Polyester Urethane Elastomers. Macromolecules 1980, 13, 248-252. [CrossRef]

14. von der Assen, N.; Bardow, A. Life cycle assessment of polyols for polyurethane production using $\mathrm{CO}_{2}$ as feedstock: Insights from an industrial case study. Green Chem. 2014, 16, 3272-3280. [CrossRef]

15. Liu, S.; Miao, Y.; Qiao, L.; Qin, Y.; Wang, X.; Chen, X.; Wang, F. Controllable synthesis of a narrow polydispersity $\mathrm{CO}_{2}$-based oligo(carbonate-ether) tetraol. Polym. Chem. 2015, 6, 7580-7585. [CrossRef]

16. Park, J.E.; Kim, W.K.; Hwang, D.Y.; Choi, G.H.; Suh, D.H. Thermally Stable Bio-Based Aliphatic Polycarbonates with QuadraCyclic Diol from Renewable Sources. Macromol. Res. 2018, 26, 246-253. [CrossRef]

17. Kwiatkowski, K.; Nachman, M. The Abrasive Wear Resistance of the Segmented Linear Polyurethane Elastomers Based on a Variety of Polyols as Soft Segments. Polymers 2017, 9, 705. [CrossRef]

18. Akindoyo, J.O.; Beg, M.D.H.; Ghazali, S.; Islam, M.R.; Jeyaratnam, N.; Yuvaraj, A.R. Polyurethane types, synthesis and applications-A review. Rsc Adv. 2016, 6, 114453-114482. [CrossRef]

19. Holten-Andersen, N.; Jaishankar, A.; Harrington, M.J.; Fullenkamp, D.E.; DiMarco, G.; He, L.H.; Lee, K.Y.C. Metal-coordination: Using one of nature's tricks to control soft material mechanics. J. Mater. Chem. B 2014, 2, 2467-2472. [CrossRef]

20. Wang, Z.; Xie, C.; Yu, C.; Fei, G.; Xia, H. A Facile Strategy for Self-Healing Polyurethanes Containing Multiple Metal-Ligand Bonds. Macromol. Rapid Commun. 2018, 39, e1700678. [CrossRef]

21. Li, C.; Zuo, J. Self-Healing Polymers Based on Coordination Bonds. Adv. Mater. 2019, 32, e1903762. [CrossRef] [PubMed]

22. Liu, S.; Oderinde, O.K.; Hussain, I.; Yao, F.; Fu, G. Dual ionic cross-linked double network hydrogel with self-healing, conductive, and force sensitive properties. Polymer 2018, 144, 111-120. [CrossRef] 
23. Zou, C.; Chen, C.L. Polar-functionalized, crosslinkable, self-Healing, and photoresponsive polyolefins. Angew. Chem. Int. Edit. 2020, 132, 403-410.

24. Li, X.; Li, W.; Wang, X.; Guo, H.; Wang, R.; Guo, X.; Li, C.; Jia, X. Enhanced adhesion force based on microphase separation induced by complexation of ferric ions and polyurethane matrix. J. Appl. Polym. Sci. 2018, 135. [CrossRef]

25. Li, C.-H.; Wang, C.; Keplinger, C.; Zuo, J.-L.; Jin, L.; Sun, Y.; Zheng, P.; Cao, Y.; Lissel, F.; Linder, C.; et al. A highly stretchable autonomous self-healing elastomer. Nat. Chem. 2016, 8, 618-624. [CrossRef] [PubMed]

26. Lai, J.; Li, L.; Wang, D.-P.; Zhang, M.-H.; Mo, S.-R.; Wang, X.; Zeng, K.-Y.; Li, C.-H.; Jiang, Q.; You, X.-Z.; et al. A rigid and healable polymer cross-linked by weak but abundant $\mathrm{Zn}(\mathrm{II})$-carboxylate interactions. Nat. Commun. 2018, 9, 1-9. [CrossRef]

27. Liang, H.; Wang, S.; He, H.; Wang, M.; Liu, L.; Lu, J.; Zhang, Y.; Zhang, C. Aqueous anionic polyurethane dispersions from castor oil. Ind. Crop. Prod. 2018, 122, 182-189. [CrossRef]

28. Li, K.; Shen, Y.; Fei, G.; Wang, H.; Li, J. Preparation and properties of castor oil/pentaerythritol triacrylate-based UV curable waterborne polyurethane acrylate. Prog. Org. Coat. 2015, 78, 146-154. [CrossRef]

29. Tian, J.; Liu, S.; Luo, Y.L.; Sun, X.P. Fe (III)-based coordination polymer nanoparticles: Peroxidase-like catalytic activity and their application to hydrogen peroxide and glucose detection. Catal. Sci. Technol. 2012, 2, 432-436. [CrossRef]

30. Xu, J.; Jin, R.; Duan, L.; Ren, X.; Gao, G. Tough, adhesive and conductive polysaccharide hydrogels mediated by ferric solution. Carbohydr. Polym. 2019, 211, 1-10. [CrossRef] [PubMed]

31. Li, J.H.; Zhang, G.P.; Deng, L.B.; Zhao, S.F.; Gao, Y.J.; Jiang, K.; Sun, R.; Wong, C.P. In situ polymerization of mechanically reinforced, thermally healable graphene oxide/polyurethane composites based on Diels-Alder chemistry. J. Mater. Chem. A 2014, 2, 20642-20649. [CrossRef]

32. Li, Y.; Pan, D.; Chen, S.; Wang, Q.; Pan, G.; Wang, T. In situ polymerization and mechanical, thermal properties of polyurethane/graphene oxide/epoxy nanocomposites. Mater. Des. 2013, 47, 850-856. [CrossRef]

33. Li, X.; Mignard, N.; Taha, M.; Prochazka, F.; Chen, J.; Zhang, S.; Becquart, F. Thermoreversible Supramolecular Networks from Poly(trimethylene Carbonate) Synthesized by Condensation with Triuret and Tetrauret. Macromolecules 2019, 52, 6585-6599. [CrossRef]

34. Guo, S.; Chen, C.; Luo, W.; Liu, F. Research on the Thermal Decomposition Reaction Kinetics and Mechanism of Pyridinol-Blocked Isophorone Diisocyanate. Materials 2016, 9, 110. [CrossRef] [PubMed]

35. Ma, L.; Song, L.; Wang, H.; Fan, L.; Liu, B. Synthesis and characterization of poly(propylene carbonate) glycol-based waterborne polyurethane with a high solid content. Prog. Org. Coat. 2018, 122, 38-44. [CrossRef]

36. Favero, D.; Marcon, V.; Figueroa, C.A.; Gómez, C.M.; Cros, A.; Garro, N.; Sanchis, M.J.; Carsí, M.; Bianchi, O. Effect of chain extender on the morphology, thermal, viscoelastic, and dielectric behavior of soybean polyurethane. J. Appl. Polym. Sci. 2021, 138, 50709. [CrossRef]

37. Wen, J.; Jia, Z.; Zhang, X.; Pan, M.; Yuan, J.; Zhu, L. Tough, thermo-Responsive, biodegradable and fast self-healing polyurethane hydrogel based on microdomain-closed dynamic bonds design. Mater. Today Commun. 2020, 25, 101569. [CrossRef]

38. Liu, W.H.; Etschmann, B.; Brugger, J.; Spiccia, L.; Foran, G.; Mclnnes, B. UV-Vis spectrophotometric and XAFS studies of ferric chloride complexes in hyper-saline LiCl solutions at 25-90 ${ }^{\circ} \mathrm{C}$. Chem. Geol. 2006, 231, 326-349. [CrossRef]

39. Mi, H.-Y.; Salick, M.R.; Jing, X.; Jacques, B.R.; Crone, W.C.; Peng, X.-F.; Turng, L.-S. Characterization of thermoplastic polyurethane/polylactic acid (TPU/PLA) tissue engineering scaffolds fabricated by microcellular injection molding. Mater. Sci. Eng. C 2013, 33, 4767-4776. [CrossRef]

40. Kojio, K.; Nakashima, S.; Furukawa, M. Microphase-separated structure and mechanical properties of norbornane diisocyanatebased polyurethanes. Polymer 2007, 48, 997-1004. [CrossRef]

41. Yeo, J.C.C.; Muiruri, J.K.; Koh, J.J.; Thitsartarn, W.; Zhang, X.; Kong, J.; Lin, T.T.; Li, Z.; He, C. Bend, Twist, and Turn: First Bendable and Malleable Toughened PLA Green Composites. Adv. Funct. Mater. 2020, 30, 2001565. [CrossRef]

42. Day, M.; Cooney, J.; MacKinnon, M. Degradation of contaminated plastics: A kinetic study. Polym. Degrad. Stab. 1995, 48, 341-349. [CrossRef]

43. Roy, P.; Surekha, P.; Raman, R.; Rajagopal, C. Investigating the role of metal oxidation state on the degradation behaviour of LDPE. Polym. Degrad. Stab. 2009, 94, 1033-1039. [CrossRef]

44. Nisar, M.; Thue, P.S.; Heck, C.A.; Geshev, J.; Lima, E.C. Polyethylene nanocomposites with Ni, Co, and Fe carbon-based magnetic fillers. Polym. Eng. Sci. 2020, 60, 988-995. [CrossRef] 